\title{
Differential Levels of Cecal Colonization by Salmonella Enteritidis in Chickens Triggers Distinct Immune Kinome Profiles
}

\author{
Christina L. Swaggerty ${ }^{*}$, Michael H. Kogut ${ }^{1}$, Haiqi He ${ }^{1}$, Kenneth J. Genovese', \\ Casey Johnson ${ }^{2}$ and Ryan J. Arsenault ${ }^{2}$
}

${ }^{1}$ U.S. Department of Agriculture, Agricultural Research Service, College Station, TX, United States, ${ }^{2}$ Department of Animal and Food Sciences, University of Delaware, Newark, DE, United States

Salmonella enterica serovar Enteritidis are facultative intracellular bacteria that cause disease in numerous species. Salmonella-related infections originating from poultry and/ or poultry products are a major cause of human foodborne illness with $S$. Enteritidis the leading cause worldwide. Despite the importance of Salmonella to human health and chickens being a reservoir, little is known of the response to infection within the chicken gastrointestinal tract. Using chicken-specific kinome immune peptide arrays we com-

OPEN ACCESS

Edited by:

Wageha Awad, Veterinärmedizinische Universität

Wien, Austria

Reviewed by:

Filip Boyen,

Ghent University, Belgium

Lisa Bielke,

The Ohio State University, United States

*Correspondence:

Christina L. Swaggerty

christi.swaggerty@ars.usda.gov

Specialty section:

This article was submitted to Veterinary Infectious Diseases,

a section of the journal

Frontiers in Veterinary Science

Received: 25 September 2017 Accepted: 28 November 2017 Published: 13 December 2017

Citation:

Swaggerty $\mathrm{CL}$, Kogut $\mathrm{MH}, \mathrm{He} \mathrm{H}$, Genovese KJ, Johnson C and Arsenault RJ (2017) Differential Levels of Cecal Colonization by Salmonella

Enteritidis in Chickens Triggers

Distinct Immune Kinome Profiles.

Front. Vet. Sci. 4:214.

doi: 10.3389/fvets.2017.00214 pared a detailed kinomic analysis of the chicken jejunal immune response in a single line of birds with high and low Salmonella loads. Four-day-old chicks were challenged with S. Enteritidis ( $10^{5} \mathrm{cfu}$ ) and cecal content and a section of jejunum collected at three times: early [4-7 days post-infection (dpi)], middle (10-17 dpi), and late (24-37 dpi). Salmonella colonization was enumerated and birds with the highest $(n=4)$ and lowest $(n=4)$ loads at each time were selected for kinomic analyses. Key biological processes associated with lower loads of Salmonella clustered around immune responses, including cell surface receptor signaling pathway, positive regulation of cellular processes, defense response, innate immune response, regulation of immune response, immune system process, and regulation of signaling. Further evaluation showed specific pathways including chemokine, Jak-Stat, mitogen activated protein kinase, and T cell receptor signaling pathways were also associated with increased resistance. Collectively, these findings demonstrate that it is possible to identify key mechanisms and pathways that are associated with increased resistance against $S$. Enteritidis cecal colonization in chickens. Therefore, providing a foundation for future studies to identify specific proteins within these pathways that are associated with resistance, which could provide breeders additional biomarkers to identify birds naturally more resistant to this important foodborne pathogen.

Keywords: chicken, kinome, peptide array, resistance, Salmonella

\begin{abstract}
Abbreviations: BP, biological process; cfu, colony forming units; $C_{t}$, threshold cycle; dpi, days post-infection; EDTA, ethylenediaminetetraacetic acid; EGTA, ethylene glycol tetraacetic acid; ERK, extracellular signal-regulated kinase; FDR, false discovery rate; GO, gene ontology; IL, interleukin; JNK, c-Jun N-terminal kinase; KEGG, Kyoto Encyclopedia of Genes and Genomes; MAPK, mitogen-activated protein kinase; PBS, phosphate buffered saline; PIIKA2, Platform for Intelligent Integrated Kinome Analysis; PLCG1, Phospholipase C gamma 1; Pyk2, protein tyrosine kinase 2; qRT-PCR, quantitative real-time Reverse Transcriptase-PCR; S. Enteritidis, Salmonella enterica serovar Enteritidis; STRING, Search Tool for the Retrieval of Interacting Genes; USDA, United States Department of Agriculture; XLT-NN, XLT4 agar base plates with XLT4 supplement and nalidixic acid and novobiocin.
\end{abstract}




\section{INTRODUCTION}

Salmonella enterica serovar Enteritidis (S. Enteritidis) is the leading cause of bacterial-derived foodborne illness worldwide (1), and Salmonella-related infections originating from poultry and/or poultry products are a significant cause of these human illnesses (2). Studies of global gene expression are informative, but many cellular processes are regulated independently of changes in transcription or translation through post-translational modifications of host proteins.

Phosphorylation is the predominant mechanism of posttranslational modification for regulation of protein function and has a central role in virtually every cellular event, as well as strong linkages with many diseases (3). Protein kinases are essential components of all cell signaling networks and events and, therefore, regulate fundamental biological processes (BPs) ranging from cellular growth to death and all processes in between (4). Examining the active kinase enzymes responsible for these phosphorylation events can provide key information into numerous host and cellular functions; therefore, there is a considerable interest in defining kinase activities. Active peptides that represent target sites of kinase enzymes can be printed onto array surfaces/slides (5), and are emerging as an important means of characterizing kinome activity (6). Global analysis of the kinome provides information on the abundance, activity, substrate specificity, phosphorylation pattern, and mutational status (4). Our laboratory has designed and developed chickenspecific arrays targeting immune and metabolism kinome activities $(7,8)$. Kinome analysis using peptide arrays provide site-specific information, display similar biochemical properties to the full protein, and have demonstrated considerable potential as a cost-effective, high-throughput approach for defining phosphorylation-mediated events (9); therefore, potentially making it possible to identify specific biomarkers associated with a desired phenotype.

Previously, our laboratory developed a novel selection method based on identification and selection of chickens with naturally high levels of pro-inflammatory mediators, including interleukin (IL) 6, CXCLi2, and CCLi2 and demonstrated the resultant chickens are more resistant to the foodborne pathogen $S$. Enteritidis (10) and other key foodborne and poultry pathogens (11-13). While our original selection strategy proved effective, an approach utilizing kinome analysis could provide a new molecular-based tool that offers the potential for highthroughput screening and selection of chickens. Identification of specific biomarkers that the poultry industry could use to select individual birds that are more resistant to cecal colonization with $S$. Enteritidis would be beneficial to the industry. This could potentially lead to either fewer $S$. Enteritidis positive birds entering the processing plant or reducing the load of bacteria the birds are carrying and, therefore, fewer positive chicken products reaching the consumer.

Within a single genetic line of birds, one would expect to find individuals that are more or less susceptible to Salmonella than some flock mates. The objectives of this study were to (1) identify chickens within a single genetic population with high and low loads of $S$. Enteritidis cecal colonization following an oral challenge, (2) perform innate immune kinome analysis to monitor kinase-mediated signaling activity on jejunal samples from non-challenged, high load $S$. Enteritidis, and low load $S$. Enteritidis birds at three distinct time points, and (3) identify the immunological processes and signaling pathways associated with enhanced resistance to $S$. Enteritidis cecal colonization within a single line of chickens at three times over the 42-day grow-out.

\section{MATERIALS AND METHODS}

\section{Experimental Animals}

All experiments were conducted according to guidelines established by the United States Department of Agriculture (USDA) animal care and use committee, which operates in accordance with established principles (14). Broiler chickens from a single genetic lineage were obtained from a commercial hatchery. At hatch, straight-run (mixed sexes) chicks were placed in floor pens $(4 \mathrm{~m} \times 4 \mathrm{~m})$ containing wood shavings, supplemental heat, water and a balanced, un-medicated corn, and soybean meal-based chick starter diet ad libitum. The feed contained 23\% protein and 3,200 kcal of metabolizable energy/ $/ \mathrm{kg}$ of diet, and all other nutrient levels met or exceeded established requirements (15). The birds were not vaccinated or given any medications during the course of the study.

\section{Bacteria Preparation}

A poultry isolate of Salmonella enterica serovar Enteritidis (S. Enteritidis) was obtained from the National Veterinary Services Laboratory (Ames, IA, USA), and was selected for resistance to nalidixic acid and novobiocin and maintained in tryptic soy broth (Difco Laboratories, Sparks, MD, USA) containing antibiotics $(20 \mu \mathrm{g} / \mathrm{mL}$ nalidixic acid and $25 \mu \mathrm{g} / \mathrm{mL}$ novobiocin; Sigma Chemical Co., St. Louis, MO, USA). A stock culture was prepared in sterile phosphate buffered saline (PBS) and adjusted to a concentration of $1 \times 10^{9}$ colony forming units $(\mathrm{cfu}) / \mathrm{mL}$ as previously described (16). The challenges were then diluted from the $1 \times 10^{9} \mathrm{cfu} / \mathrm{mL}$ stock culture to the desired concentration. The viable cell concentration of the challenge dose for each experiment was determined by colony counts on XLT4 agar base plates with XLT4 supplement (Difco) and nalidixic acid and novobiocin (XLT-NN).

\section{Bacterial Challenge and Recovery}

Four-day-old broiler chicks were challenged orally with $S$. Enteritidis $\left(0.5 \mathrm{~mL} ; 4.8 \times 10^{5} \mathrm{cfu} / \mathrm{chick}\right)$ while controls were administered sterile PBS; $0.5 \mathrm{~mL}$. Cloacal swabs were collected 3 days post challenge to confirm the controls were not infected and that all birds that were challenged were culture positive for $S$. Enteritidis. Briefly, a sterile cotton swab was gently inserted into the cloaca and a fecal sample was collected. The entire swab and sample for each bird was then placed into a separate tube containing tetrathionate enrichment broth (10 mL, Difco) and incubated overnight at $41^{\circ} \mathrm{C}$. Following enrichment, $10 \mu \mathrm{L}$ were streaked onto XLT-NN plates, incubated $24 \mathrm{~h}$ at $41^{\circ} \mathrm{C}$, then the plates examined for non-lactose fermenting NN-resistant Salmonella colonies. Representative colonies were confirmed positive by plate agglutination using specific Group $D_{1}$ antisera (Difco). 


\section{Sample Collection and Processing}

One-day-old broiler chickens were randomly distributed into two experimental groups: non-infected control and infected $(n=50)$. Early samples were collected between 4 and 7 days postinfection (dpi), middle samples were collected between 10 and $17 \mathrm{dpi}$, and late samples were collected between 24 and $37 \mathrm{dpi}$. The experiments were conducted on two separate occasions.

Control and infected chickens $(n=10)$ were euthanized by cervical dislocation and necropsied at three timeframes (early, middle, and late) over the course of a 42-day grow-out. The cecum from each chicken was removed aseptically, and the contents $(0.25 \mathrm{~g})$ were serially diluted to $1: 100,1: 1,000$, or $1: 10,000$ and spread onto XLT-NN plates to enumerate $S$. Enteritidis. The plates were incubated at $41^{\circ} \mathrm{C}$ for $24 \mathrm{~h}$, and the number of NN-resistant $S$. Enteritidis cells per g of cecal contents determined. A piece of jejunum (100 mg) was collected and rinsed with PBS to remove content and then placed into a cryovial containing $1.5 \mathrm{~mL}$ RNAlater RNA stabilization reagent (Qiagen, Valencia, CA, USA) and stored at $-20^{\circ} \mathrm{C}$ until tissue homogenization and RNA isolation was performed for quantitative real-time Reverse Transcriptase-PCR (qRT-PCR). Additionally, a section of jejunum (100 mg) was collected from each bird, rinsed with PBS to remove content, and then immediately flash frozen in liquid nitrogen to preserve kinase enzymatic activity for the array. Samples were taken from liquid nitrogen and transferred to a $-80^{\circ} \mathrm{C}$ freezer until further experimental procedures were conducted. Following microbiological analysis of the cecal contents (described previously), the jejunum tissues from four birds with the highest and four birds with the lowest levels of recoverable $S$. Enteritidis (out of the 10 birds per time) were used for the peptide arrays.

\section{Kinome (Peptide) Array}

PepStar peptide microarrays were obtained from JPT Peptide Technologies GmbH (Berlin, Germany), and the peptide array protocol was carried out as previously described (6) with the following modifications $(8,17)$. Jejunum tissue samples were weighed to obtain a consistent $40 \mathrm{mg}$ sample for the array protocol. Samples were homogenized by a hand-held TissueRuptor (Qiagen, Valencia, CA, USA) in $100 \mu \mathrm{L}$ of lysis buffer $(20 \mathrm{mM}$ Tris- $\mathrm{HCl}$ $\mathrm{pH}$ 7.5, $150 \mathrm{mM} \mathrm{NaCl}, 1 \mathrm{mM}$ Ethylenediaminetetraacetic acid, $1 \mathrm{mM}$ ethylene glycol tetraacetic acid, 1\% Triton X-100, $2.5 \mathrm{mM}$ sodium pyrophosphate, $1 \mathrm{mM} \mathrm{Na} \mathrm{VO}_{4}, 1 \mathrm{mM} \mathrm{NaF}, 1 \mu \mathrm{g} / \mathrm{mL}$ leupeptin, $1 \mathrm{~g} / \mathrm{mL}$ aprotinin, and $1 \mathrm{mM}$ Phenylmethylsulphonyl fluoride). All chemicals purchased from Sigma-Aldrich, Co. (St. Louis, MO, USA) unless otherwise indicated.

\section{Antibody Array}

The Phospho Explorer Antibody Array kit (catalog PEX100; Full Moon BioSystems, Sunnyvale, CA, USA) consists of over 1,300 antibodies from over 30 signaling pathways and is an alternative approach to procuring phosphor-specific antibodies individually and performing numerous western blot assays. The protocol was carried out as per manufacturer's instructions with the exception that the tissue was homogenized using a hand-held TissueRuptor (Qiagen, Valencia, CA, USA) instead of the bead and vortex method suggested in the kit.

\section{Data Analysis: Kinome and Antibody Arrays}

Data normalization and analysis was performed for both the kinome and antibody microarrays as described (17). Images were gridded using GenePix Pro software, and the spot intensity signal was collected as the mean of pixel intensity using local feature background intensity calculation with the default scanner saturation level. The data was then analyzed using the Platform for Intelligent Integrated Kinome Analysis (PIIKA2) peptide array analysis software (http://saphire.usask.ca/saphire/piika/ index.html). Briefly, the resulting data points were normalized to eliminate variance due to technical variation, for example, random variation in staining intensity between arrays or between array blocks within an array. Variance stabilization and normalization was performed. Note: as the arrays were printed with triplicate peptide blocks there are three values for each peptide. Using the normalized data set comparisons between treatment and control groups were performed, calculating fold-change and a significance $P$-value. The $P$-value is calculated by conducting a one-sided paired $t$-test between treatment and control values for a given peptide.

This consistent analysis method facilitates a more direct comparison between the two distinct array datasets and allows for a statistically robust analysis of the phosphorylation events being measured. Gene ontology (GO) and Kyoto Encyclopedia of Genes and Genomes (KEGG) pathway analysis was performed by uploading the statistically significant peptide lists to the Search Tool for the Retrieval of Interacting Genes (STRING ${ }^{1}$ ) (18).

\section{Isolation of Total RNA for qRT-PCR}

Tissue homogenization was performed using a BeadBug microtube homogenizer (Benchmark Scientific, Edison, NJ, USA). Briefly, a piece of tissue (30-40 mg) was removed from RNAlater and placed in a $2 \mathrm{~mL}$ prefilled tube containing $1.5 \mathrm{~mm}$ high impact zirconium beads (TriplePure M-Bio Grade; Benchmark Scientific). Lysis buffer (350 $\mu \mathrm{L}$; RNeasy Mini Kit; Qiagen) was added and the sample was homogenized in the BeadBug for 2 min on the maximum speed. Total RNA was then isolated from the homogenized samples according to the manufacturer's instructions, eluted with $50 \mu \mathrm{L}$ RNase-free water, and stored at $-80^{\circ} \mathrm{C}$ until qRT-PCR analyses performed.

\section{Quantitative Real-time RT-PCR}

Interleukin 6 and CXCLi2 mRNA expression was quantified using a well-described method. Primers and probes for cytokines, chemokines, and 28S RNA-specific amplification has been previously described (19-21). The qRT-PCR was performed using the TaqMan one-step RT-PCR master mix reagents (Applied Biosystems, Branchburg, NJ). Amplification and detection of specific products were performed using the Applied Biosystems 7500 Fast Real-Time PCR System with the following cycle profile: one cycle of $48^{\circ} \mathrm{C}$ for $30 \mathrm{~min}, 95^{\circ} \mathrm{C}$ for $20 \mathrm{~s}$, and 40 cycles of $95^{\circ} \mathrm{C}$ for $3 \mathrm{~s}$ and $60^{\circ} \mathrm{C}$ for $30 \mathrm{~s}$. Quantification was based on the increased fluorescence detected by the 7500 Fast Sequence

${ }^{1}$ www.phosphosite.org. 
Detection System due to hydrolysis of the target-specific probes by the $5^{\prime}$ nuclease activity of the $r$ Tth DNA polymerase during PCR amplification. To correct for differences in RNA levels between samples within the experiment, the correction factor for each sample was calculated by dividing the mean threshold cycle $\left(C_{t}\right)$ value for $28 \mathrm{~S}$ rRNA-specific product for each sample, by the overall mean $C_{t}$ value for the $28 \mathrm{~S}$ rRNA-specific product from all samples. The corrected cytokine mean is calculated: (Average of each replicate $\times$ cytokine slope)/28s slope $\times 28 \mathrm{~s}$ correction factor. The data shown are corrected $40-C_{\mathrm{t}}$ values.

\section{Statistical Analyses}

The mean and SEM for each cytokine/chemokine were calculated at each time and statistical analyses performed (Student's $t$-test); comparisons were made between a single timeframe

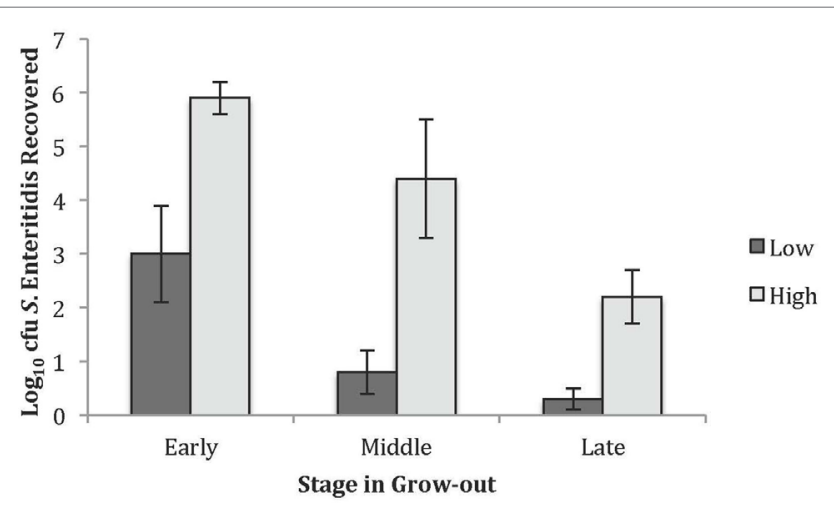

FIGURE 1 | Recovered Salmonella Enteritidis in the high and low groups used for the peptide and antibody arrays. The average $\log _{10}$ colony forming units recovered for the low and high $S$. Enteritidis groups at the early, middle, and late times. comparing the birds with high and low levels of $S$. Enteritidis cecal colonization. No statistical analysis was performed for the differences in bacterial load. Details for the array analysis are provided in the Data Analysis: Kinome and Antibody Arrays section described above. For all analyses, significance was considered if $P \leq 0.05$.

\section{RESULTS}

\section{S. Enteritidis Colonization}

Cloacal swabs were collected on all birds in the study three days post challenge to confirm the controls were not infected and that all challenged birds were culture positive for the challenge strain of $S$. Enteritidis. All birds administered the challenge were positive for $S$. Enteritidis while all of the controls were negative (data not shown).

Within this single line of birds, varying levels of $S$. Enteritidis cecal colonization were observed and, therefore, studying birds with relatively high and low numbers of recoverable $S$. Enteritidis was pursued. The levels of $S$. Enteritidis colonization for the high and low groups at each timeframe are summarized in Figure 1. Chickens in the early time point and designated to the low group had $3.0 \pm 0.9 \log _{10} \mathrm{cfu}$ of recoverable $S$. Enteritidis while the birds in the high group had $5.9 \pm 0.3 \log _{10} \mathrm{cfu}$. The values for the middle group were $0.8 \pm 0.4$ and $4.4 \pm 1.1 \log _{10} \mathrm{cfu} S$. Enteritidis for the low and high groups, respectively. The recoverable $S$. Enteritidis continued to decline by the late timeframe and were $0.3 \pm 0.2$ and $2.2 \pm 0.5 \log _{10}$ cfu $S$. Enteritidis for the low and high groups, respectively.

\section{GO BPs}

The GO Consortium assigns defined terms representing gene product properties and is broken into three categories: cellular

TABLE 1 | Gene ontology (GO) biological process (BPS) terms identified using the peptide array and the number of differentially phosphorylated peptides associated with high and low loads of Salmonella Enteritidis colonization.

\begin{tabular}{|c|c|c|c|c|c|c|c|}
\hline GO ID & BP term & $\begin{array}{c}\text { Early } \\
\text { low SE }\end{array}$ & $\begin{array}{c}\text { Early } \\
\text { high SE }\end{array}$ & $\begin{array}{l}\text { Middle } \\
\text { low SE }\end{array}$ & $\begin{array}{l}\text { Middle } \\
\text { high SE }\end{array}$ & $\begin{array}{c}\text { Late } \\
\text { low SE }\end{array}$ & $\begin{array}{c}\text { Late } \\
\text { high SE }\end{array}$ \\
\hline G0.0050776 & Regulation of immune response & 60 & 26 & 52 & 40 & 41 & 43 \\
\hline G0.0045087 & Innate immune response & 61 & 31 & 55 & 42 & 44 & 43 \\
\hline GO.0002764 & Immune response-regulating signaling pathway & 48 & 21 & 45 & 34 & 34 & 35 \\
\hline G0.0002768 & Immune response-regulating cell surface receptor signaling pathway & 40 & 17 & 38 & 30 & 31 & 28 \\
\hline G0.0002684 & Positive regulation of immune system process & 45 & 21 & 45 & 29 & 32 & 29 \\
\hline G0.0002376 & Immune system process & 60 & 28 & 63 & 47 & 46 & 42 \\
\hline G0.0034097 & Response to cytokine & 37 & 16 & 26 & 15 & 24 & 22 \\
\hline G0.0043549 & Regulation of kinase activity & 38 & 17 & 40 & 33 & 25 & 28 \\
\hline GO.0034142 & TLR4 signaling pathway & 18 & 7 & 17 & 11 & 10 & 9 \\
\hline G0.0000165 & Mitogen activated protein kinase cascade & 20 & 8 & 19 & 21 & 12 & 12 \\
\hline GO.0009617 & Response to bacterium & 23 & 6 & 16 & 11 & 14 & 18 \\
\hline G0.0048522 & Positive regulation of cellular process & 77 & 36 & 66 & 52 & 49 & 54 \\
\hline G0.0006935 & Chemotaxis & 27 & 12 & 22 & 22 & 19 & 7 \\
\hline G0.0006909 & Phagocytosis & 16 & 6 & 11 & 8 & 12 & 12 \\
\hline G0.0006954 & Inflammatory response & 17 & 6 & 9 & 10 & 11 & 11 \\
\hline G0.0001932 & Regulation of protein phosphorylation & 49 & 22 & 48 & 38 & 29 & 37 \\
\hline G0.0006952 & Defense response & 67 & 30 & 58 & 43 & 47 & 43 \\
\hline GO.0007166 & Cell surface receptor signaling pathway & 81 & 42 & 72 & 58 & 57 & 60 \\
\hline
\end{tabular}

SE, S. Enteritidis 
component, molecular function, and BP. The BP terms include operations or sets of molecular events with a defined beginning and end that pertain to the functioning of the integrated living units. ${ }^{2}$ Using STRING functionality, GO results for BP were generated for each dataset. The total number of BPs associated with each time and bacterial load were: early low $=1,218$; early

${ }^{2} \mathrm{http} / /$ geneontology.org/page/ontology-documentation. high $=617 ;$ middle low $=1,084 ;$ middle high $=1,001$; late low $=942$; and late high $=1,049$ (data not shown). The most significant (based on $P$-value) immunologically relevant GO BP were selected for further analysis. Analysis of the kinome data showed distinct differences in the observed BP between the loads of bacteria, and some of the central differences are provided in Table 1. Each term listed had a false discovery rate (FDR) $P \leq 0.01$. The BP with high numbers of peptide phosphorylation events associated with low levels of $S$. Enteritidis colonization regardless

TABLE 2 | Kyoto Encyclopedia of Genes and Genomes (KEGG) pathways identified with the peptide array at the early stage infections in chickens with high and low levels of Salmonella Enteritidis colonization.

\begin{tabular}{|c|c|c|c|}
\hline High S. Enteritidis & Number of peptides & Low S. Enteritidis & Number of peptides \\
\hline B cell receptor signaling pathway & 4 & B cell receptor signaling pathway & 4 \\
\hline \multirow{21}{*}{$\begin{array}{l}\text { Mitogen activated protein kinase (MAPK) signaling } \\
\text { pathway }\end{array}$} & 6 & Chagas disease & 4 \\
\hline & & Chemokine signaling pathway & 4 \\
\hline & & Epithelial cell signaling pathway in Helicobacter pylori infection & 2 \\
\hline & & ErbB signaling pathway & 6 \\
\hline & & Fc $\varepsilon$ RI signaling pathway & 5 \\
\hline & & Fc- $\gamma$ receptor-mediated phagocytosis & 5 \\
\hline & & Focal adhesion & 6 \\
\hline & & GnRH signaling pathway & 3 \\
\hline & & Insulin signaling pathway & 7 \\
\hline & & Jak-Stat signaling pathway & 7 \\
\hline & & MAPK signaling pathway & 8 \\
\hline & & mTor signaling pathway & 2 \\
\hline & & Natural killer cell mediated cytotoxicity & 6 \\
\hline & & Neurotrophin signaling pathway & 6 \\
\hline & & Osteoclast differentiation & 4 \\
\hline & & Pathways in cancer & 10 \\
\hline & & $\mathrm{T}$ cell receptor signaling pathway & 6 \\
\hline & & Toll-like receptor signaling pathway & 2 \\
\hline & & Toxoplasmosis & 3 \\
\hline & & Tuberculosis & 3 \\
\hline & & VEGF signaling pathway & 5 \\
\hline
\end{tabular}

Pathways listed in bold showed statistically significant changes at all time points in birds with either low or high loads of S. Enteritidis.

TABLE 3 | Kyoto Encyclopedia of Genes and Genomes (KEGG) pathways identified with the peptide array at the middle stage infections in chickens with high and low levels of Salmonella Enteritidis colonization.

\begin{tabular}{|c|c|c|c|}
\hline High S. Enteritidis & Number of peptides & Low S. Enteritidis & Number of peptides \\
\hline Bacterial invasion of epithelial cells & 5 & Chemokine signaling pathway & 5 \\
\hline Chemokine signaling pathway & 7 & ErbB signaling pathway & 4 \\
\hline Chronic myeloid leukemia & 4 & Fc $\varepsilon$ RI signaling pathway & 2 \\
\hline ErbB signaling pathway & 7 & Focal adhesion & 2 \\
\hline FC $\varepsilon$ RI signaling pathway & 1 & GnRH signaling pathway & 4 \\
\hline Focal adhesion & 6 & Insulin signaling pathway & 3 \\
\hline Insulin signaling pathway & 5 & Jak-Stat signaling pathway & 4 \\
\hline Mitogen activated protein kinase (MAPK) signaling pathway & 6 & Leukocyte transendothelial migration & 2 \\
\hline Natural killer cell mediated cytotoxicity & 4 & MAPK signaling pathway & 4 \\
\hline Neurotrophin signaling pathway & 6 & mTor signaling pathway & 2 \\
\hline Pathways in cancer & 6 & Neurotrophin signaling pathway & 5 \\
\hline \multirow[t]{4}{*}{ T cell receptor signaling pathway } & 4 & Pathways in cancer & 2 \\
\hline & & Regulation of actin cytoskeleton & 1 \\
\hline & & T cell receptor signaling pathway & 1 \\
\hline & & Tuberculosis & 3 \\
\hline
\end{tabular}

Pathways listed in bold showed statistically significant changes at all time points in birds with either low or high loads of S. Enteritidis. 
TABLE 4 | Kyoto Encyclopedia of Genes and Genomes (KEGG) pathways identified with the peptide array at the late stage infections in chickens with high and low levels of Salmonella Enteritidis colonization.

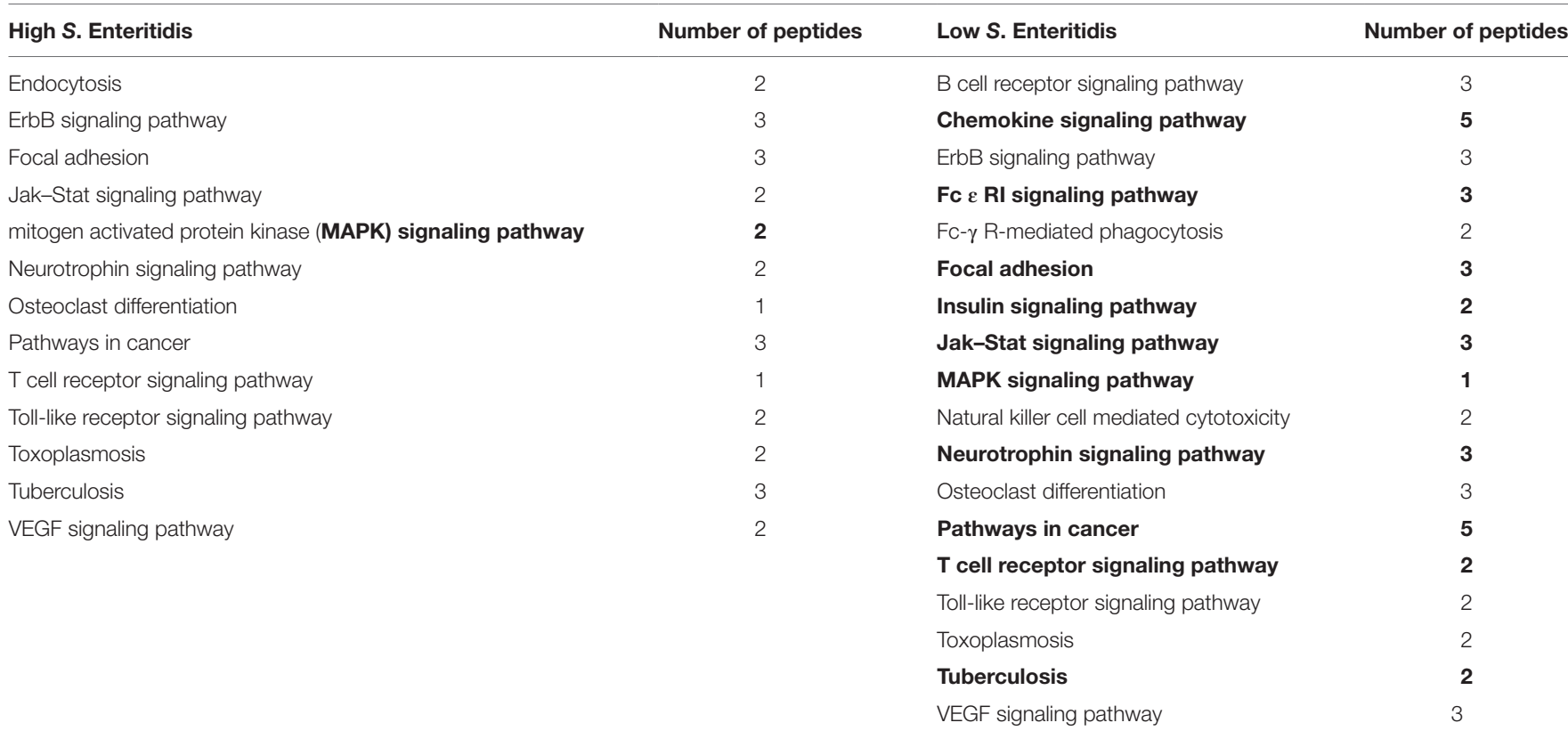

Pathways listed in bold showed statistically significant changes at all time points in birds with either low or high loads of S. Enteritidis.

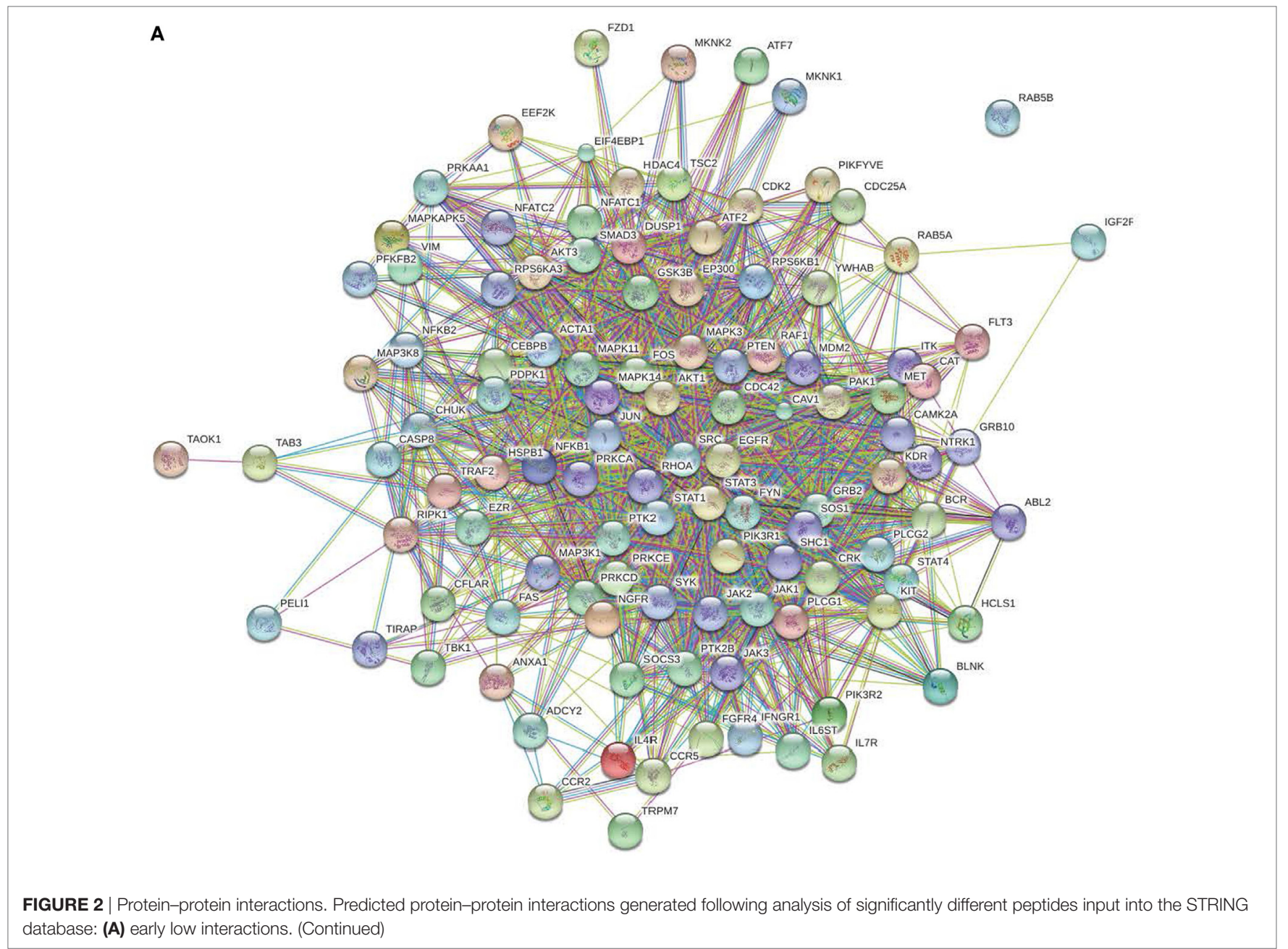




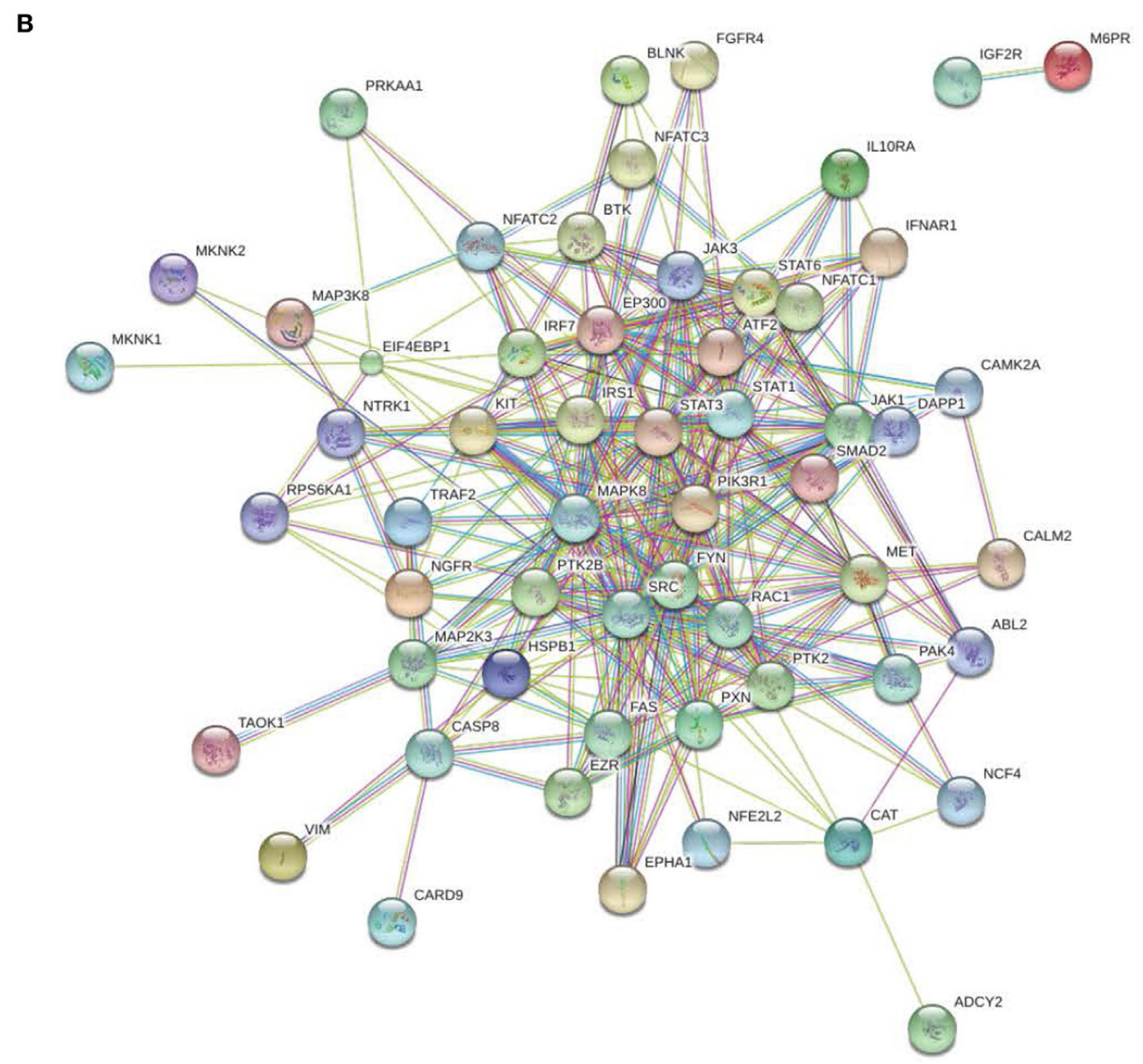

FIGURE 2 | Protein-protein interactions. Predicted protein-protein interactions generated following analysis of significantly different peptides input into the STRING database: (B) early high interactions. (Continued)

of time (early, middle, or late) are clustered around immune responses and subsequent signaling pathways and include: cell surface receptor signaling pathway, positive regulation of cellular processes, defense response, innate immune response, regulation of immune response, immune system process, and regulation of signaling. Activation of the BP were observed at the early, middle, and late infection times, but the numbers of differentially phosphorylated peptides between the low/high loads of $S$. Enteritidis were greatest at the early and middle points. By late in the infection, the numbers of peptides was similar between the birds with low and high loads of $S$. Enteritidis as might be expected based on the overall lower numbers of bacteria recovered (Figure 1). These data point to the early immune mechanisms that aid in controlling $S$. Enteritidis.

\section{KEGG Pathway Activation}

Using STRING functionality, KEGG pathway results were generated for each dataset. To ensure that changes in phosphorylation were a direct result of the infection, the results were corrected using the appropriate age-matched controls. The KEGG pathway results showed numerous pathways that were significantly different between the birds with high and low loads of $S$. Enteritidis at each time of the infection $(P \leq 0.05 \mathrm{FDR})$. In order to be included, a pathway had to be significant for each bird within a group and time. Pathways that were not significant for each bird at a specific time and bacterial load were excluded. Additionally, the numbers for a subset of the significantly different peptides within each of the KEGG pathways are also provided. The numbers shown are a small fraction of the total number of significant peptides within a specific pathway; however, as based on our criteria to be included in the dataset, a peptide had to be statistically significantly different from control for every bird in a given group (i.e., every early/low bird, early/high bird, middle/low bird, middle/high bird, late/low bird, or late/high birds).

The significant KEGG pathways observed at the early time are shown in Table 2, and the pathways for the middle and late times are provided in Tables 3 and 4, respectively. Pathways listed in bold showed statistically significant changes at all time points in birds with either low or high loads of $S$. Enteritidis. The common pathways observed in chickens with low loads of $S$. Enteritidis included: chemokine signaling pathway, Fc $\varepsilon$ RI signaling pathway, focal adhesion, insulin signaling pathway, Jak-Stat signaling pathway, mitogen-activated protein kinase (MAPK) signaling pathway, neurotrophin signaling pathway, pathways in cancer, $\mathrm{T}$ cell receptor signaling pathway, and Tuberculosis. The specific proteins associated with each of the pathways, including those 


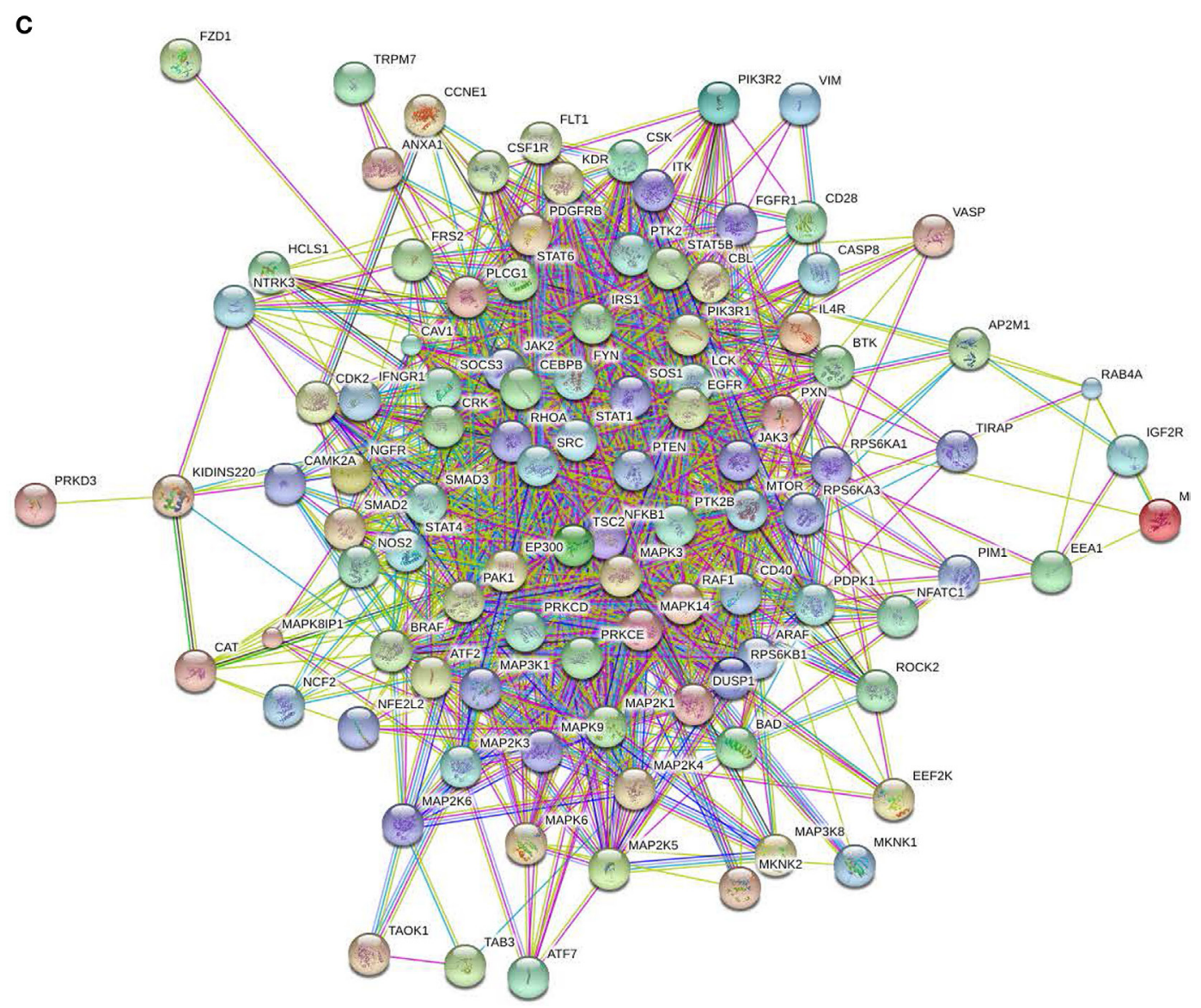

FIGURE 2 | Protein-protein interactions. Predicted protein-protein interactions generated following analysis of significantly different peptides input into the STRING database: (C) middle low interactions. (Continued)

specifically related to cancer, would also be pivotal in determining the hosts' immunological response against a challenge and/or disease. The only pathway that was significantly different at each time in birds with high levels of $S$. Enteritidis colonization was the MAPK signaling pathway.

All peptides that were statistically different $(P \leq 0.05)$ for each time were input into the STRING database (22) and diagrams depicting the protein-protein interactions were generated (Figure 2). The most striking difference in the magnitude of the protein-protein interactions was observed between the birds with low or high loads of $S$. Enteritidis colonization at the early time (Figures 2A,B, respectively). The protein-protein interactions for middle low and middle high birds are shown in Figures 2C,D, respectively, and the late low and late high interactions are shown in Figures 2E,F, respectively.

\section{Validation Using the Antibody Array}

To validate the kinome peptide array data, an antibody array containing both pan-specific and phospho-specific antibodies was employed instead of performing individual western blot analyses (8). Analysis of antibody array data via the STRING database showed similar GO BP and KEGG pathway activity at the early and middle times as observed with the kinome array; representative samples are shown in Table 5. Though outside the scope of this manuscript, but for validation purposes only, a small number of individual peptides associated with KEGG pathways identified with the kinome array (Tables 2-4) were selected and evaluated to demonstrate consistency between the kinome and antibody arrays. Phospholipase C gamma 1 (PLCG1), protein tyrosine kinase 2 (Pyk2), Raf1, and SMAD2 shared similar phosphorylation/de-phosphorylation patterns and were, in general, in agreement between the two arrays, thus further validating the kinome array results (Table 6). The antibody array was not utilized on the late samples since consistency was demonstrated at the early and middle times. Furthermore, as already described, there were fewer differences between the birds with high and low loads of $S$. Enteritidis at the late time point lessening the applicability of a comparative validation technique.

\section{Quantitative Real-time RT-PCR}

The expression of IL6 and CXCLi2 mRNA was quantified $\left(40-\mathrm{C}_{t}\right)$ in tissue from birds with high and low levels of $S$. Enteritidis cecal colonization at early, middle, and late times. Birds with lower levels of $S$. Enteritidis at the early time point had 


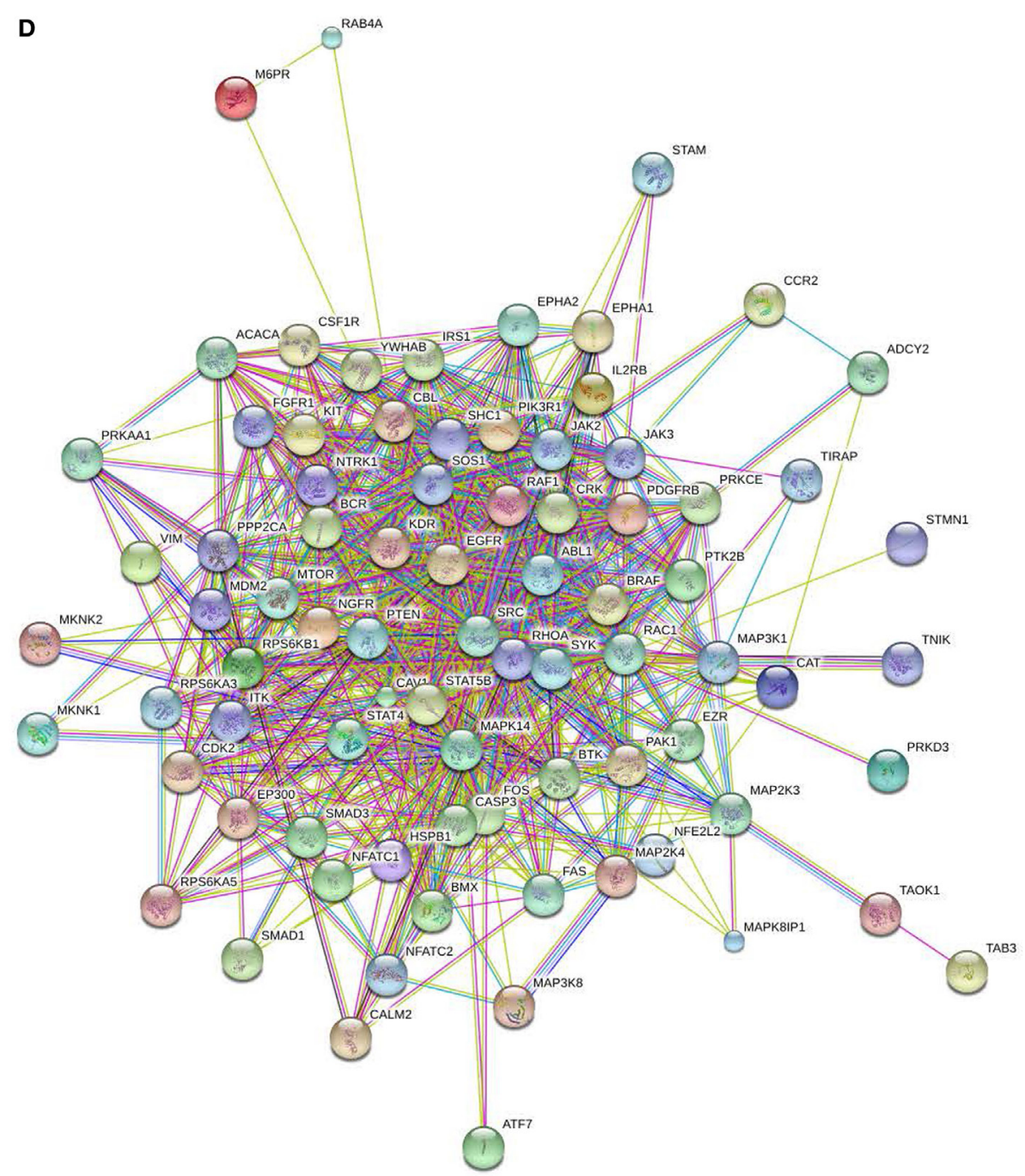

FIGURE 2 | Protein-protein interactions. Predicted protein-protein interactions generated following analysis of significantly different peptides input into the STRING database: (D) middle high interactions. (Continued)

significantly $(P \leq 0.05)$ higher mRNA expression levels of CXCLi2 than birds with higher loads of $S$. Enteritidis (14.5 and 13.6, respectively). There were no statistical differences in CXCLi2 mRNA expression at the middle and late times. There were no differences in IL6 between birds with high and low loads of $S$. Enteritidis colonization compared to one another or the respective controls at the early, middle, or late times (data not shown).

\section{DISCUSSION}

Laboratory challenges using animal models are a vital component for making scientific advances regardless of the field of study. Despite controlling for host genetics, environmental conditions, and challenge preparation and recovery methodologies, investigators accept there will be a certain amount of variability observed between individual animals. Such variability was observed within the line of birds evaluated in the present study, and despite $100 \%$ of the challenged chickens being culture positive for $S$. Enteritidis, the actual numbers of recoverable bacteria varied between individuals (Figure 1). A recent study suggests the differences in bacterial growth and immune responses seen across genetically identical mice is a result of specific immune elements that facilitate the coregulation and interconnectedness of the innate and adaptive immune responses (23). The observed differences in cecal colonization could also be due, in part, to intermittent shedding. It is widely recognized that chickens shed varying levels of $S$. Enteritidis over time $(24,25)$. Observing the different levels of cecal colonization in the study presented herein led us to hypothesize that differences may be detectable by evaluating the host kinome response and, therefore, provide valuable insight into the mechanism(s) that either limits or enables $S$. Enteritidis, one of the most important foodborne bacteria, to colonize the chicken ceca. 


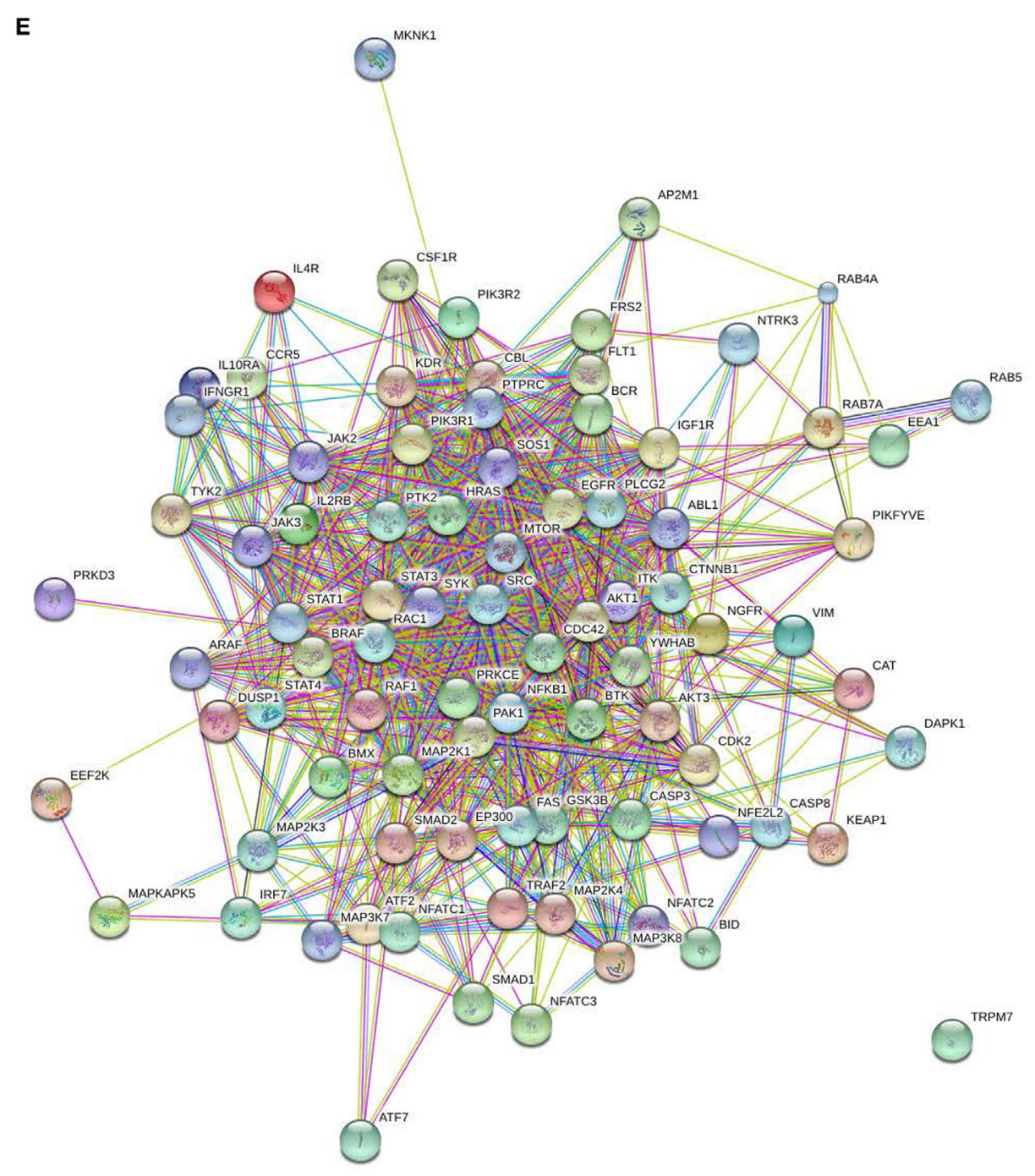

FIGURE 2 | Protein-protein interactions. Predicted protein-protein interactions generated following analysis of significantly different peptides input into the STRING database: (E) late low interactions. (Continued)

The results presented herein revealed that birds with high and low levels of cecal colonization with $S$. Enteritidis, at the time of sampling, have distinct kinome profiles (i.e., protein phosphorylation patterns). As such, key BP and immunologically related pathways associated with increased resistance within a single population of birds were identified (Tables 1-4). The signaling pathways that differed between birds with high and low loads of $S$. Enteritidis colonization include those associated with chemokine, Jak-Stat, MAPK, and T cell receptor signaling. Differences in these seminal pathways would be anticipated as several studies in poultry show that strong pro-inflammatory cytokine and chemokine responses are associated with increased resistance against disease (26-30). Moreover, differences within individual components of the MAPK signaling pathway [p38, extracellular signal-regulated kinase (ERK), c-Jun N-terminal kinase (JNK)] have been reported in chickens and turkeys. Genes within the MAPK signaling cascade were mapped and shown to be involved in resistance against Salmonella in chickens (31). Another study in chickens showed that increased resistance against $S$. Enteritidis organ invasion is associated with elevated production of p 38 and decreased production of JNK (32) while increased production of $\mathrm{p} 38$, JNK, and ERK are all influential in determining the level of resistance in turkeys (33). Involvement of the MAPK signaling pathway extends beyond mere immunological responses by the host. In fact, the virulence factors encoded by Salmonella can promote either activation or deactivation of the MAPK signaling pathway (34-36), so it is possible the observed changes are a direct result of the bacteria and not necessarily the hosts' response to the challenge. Further studies are necessary to dissect this complex host-pathogen interaction.

Additionally, KEGG analysis showed that pathways in cancer were significantly different across all times in birds with lower levels of $S$. Enteritidis cecal colonization. The authors are not 


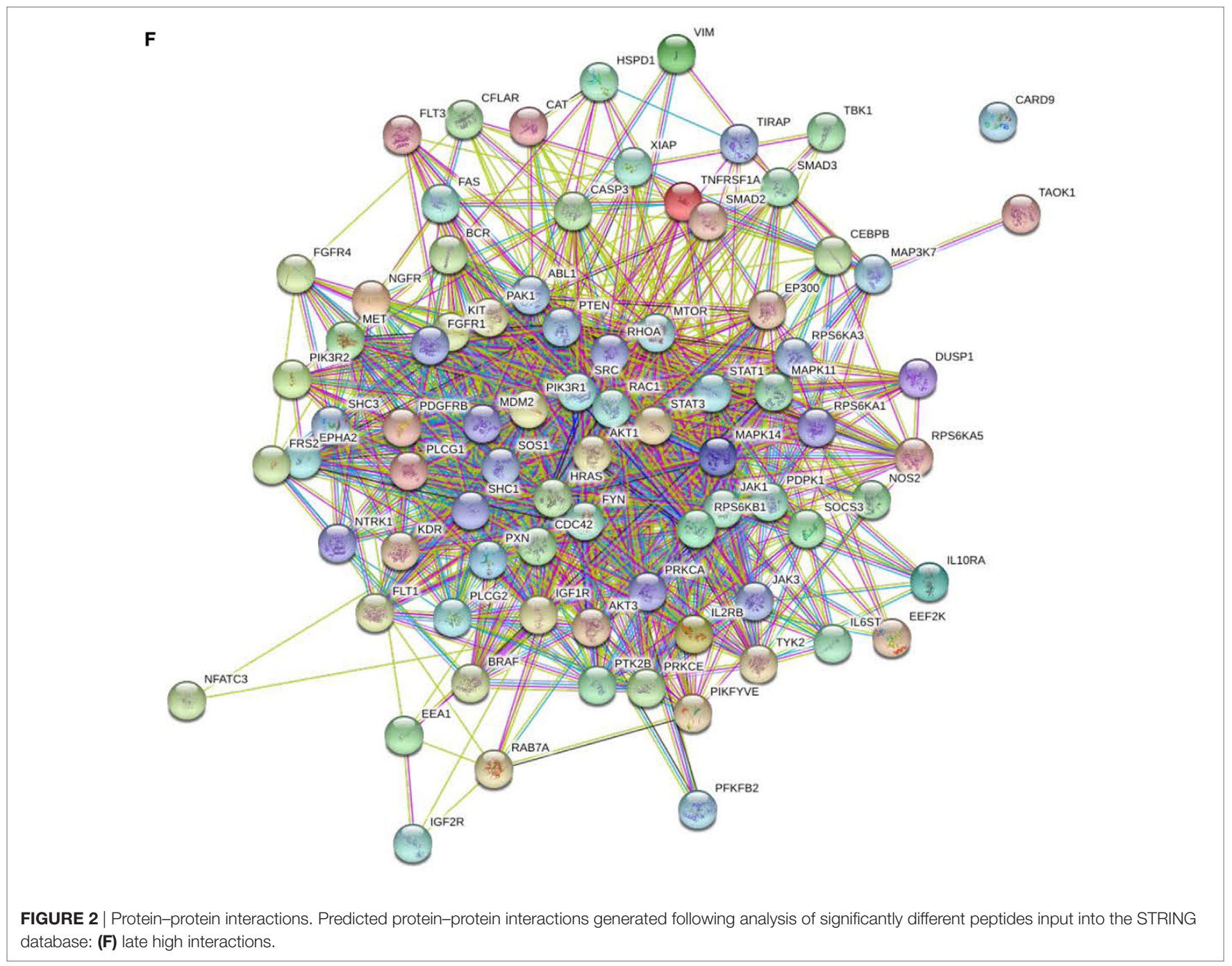

TABLE 5 | Gene ontology (GO) biological process (BP) terms and Kyoto Encyclopedia of Genes and Genomes (KEGG) pathways identified by the antibody array.

\begin{tabular}{|c|c|c|c|}
\hline \multicolumn{2}{|l|}{ BPs } & \multicolumn{2}{|c|}{ KEGG pathways } \\
\hline G0.0050776 & Regulation of immune response & $\begin{array}{l}\text { Mitogen activated protein kinase } \\
\text { (MAPK) signaling pathway }\end{array}$ & Pathways in cancer \\
\hline G0.0045087 & Innate immune response & & MAPK signaling pathway \\
\hline G0.0002764 & Immune response-regulating signaling pathway & & Neurotrophin signaling pathway \\
\hline GO.0002768 & Immune response-regulating cell surface receptor signaling pathway & & T cell receptor signaling pathway \\
\hline G0.0048522 & Positive regulation of cellular process & & \\
\hline G0.0006952 & Defense response & & \\
\hline G0.0007166 & Cell surface receptor signaling pathway & & \\
\hline
\end{tabular}

suggesting the $S$. Enteritidis challenge resulted in cancer in the birds. Of note, studies on the kinome are widely used in cancer research since virtually every cancer displays varying levels of protein and/or lipid kinase dysregulation. Therefore, kinome analysis provides meaningful insight into the pathways and families of kinases involved in specific cancers (37), which would explain why pathways affiliated with cancer are identified in the analysis tools. The specific proteins associated with each 
TABLE 6 | Fold-change in specific peptides associated with high and low loads of Salmonella Enteritidis using the peptide array and validation with the antibody array.

\begin{tabular}{|c|c|c|c|c|c|}
\hline \multirow[b]{2}{*}{ Peptide } & \multirow[b]{2}{*}{ Accession no. } & \multicolumn{2}{|c|}{ Early } & \multicolumn{2}{|c|}{ Middle } \\
\hline & & Low peptide (Ab) & High peptide (Ab) & Low peptide (Ab) & High peptide (Ab) \\
\hline Phospholipase C gamma 1 & P19174 & $-1.7^{a^{\star}}\left(-1.8^{\star}\right)$ & $-1.0(-1.0)$ & $2.4^{\star}(\mathrm{ND})$ & $1.2\left(1.5^{\star}\right)$ \\
\hline Pyk2 & Q14289 & $\mathrm{ND}\left(-1.5^{\star}\right)$ & $1.7^{\star}\left(1.9^{*}\right)$ & $\mathrm{ND}\left(1.2^{\star}\right)$ & $1.8^{\star}\left(1.3^{\star}\right)$ \\
\hline Raf1 & P04049 & $1.5^{\star}(\mathrm{ND})$ & $\mathrm{ND}(\mathrm{ND})$ & $1.2\left(1.7^{\star}\right)$ & $\mathrm{ND}\left(-2.5^{\star}\right)$ \\
\hline SMAD2 & Q15796 & $-2.8^{\star}\left(-5.3^{\star}\right)$ & $1.5^{\star}\left(1.9^{\star}\right)$ & $-1.1\left(-5.3^{\star}\right)$ & $1.9\left(-7.8^{\star}\right)$ \\
\hline
\end{tabular}

(Ab), antibody array; ND, not detected.

${ }^{a}$ Fold-change from control.

${ }^{*} P \leq 0.05$.

of the pathways, including those specifically related to cancer, would also be pivotal in determining the hosts' immunological response against a challenge and/or disease. As previously shown, kinome analysis is beneficial in dissecting pathways involved in animal studies including bovine viral diarrhea virus (38); in vitro responses against toll-like receptor agonists (39), Johne's disease in cattle $(40)$, and Salmonella in chickens $(8,41)$ demonstrating the technology is useful in providing valuable information into diverse infections that alter the normal host mechanisms.

Changes in cytokine and chemokine expression in chickens are widely reported following Salmonella enterica challenges and/or infections. In the current study, mRNA expression of CXCLi2 was upregulated early in the chickens with lower levels of $S$. Enteritidis. This finding is supported by another study showing CXCLi2 is found in the gut of newly hatched chicks and mRNA expression continues to increase the first week posthatch (42). More specifically, CXCLi2 mRNA is upregulated in Salmonella-resistant chickens $(27,43)$. CXCLi2 (formerly referred to as IL8) is a potent pro-inflammatory chemokine capable of recruiting immune cells, such as heterophils, to the site of infection (44), and heterophil recruitment is associated with increased resistance against $S$. Enteritidis (16). The role of heterophils was not considered in the current study, but increases in CXCLi2 expression have been reported in various cells and tissue types across diverse breeds of chickens (45-47). Therefore, our study is in agreement and indicates increased CXCLi2 is likely a contributing factor to the lower numbers of bacteria seen at the early time. As might be expected, no differences in CXCLi2 were observed at the middle and late times as the infection had become persistent instead of acute (41). In addition to CXCLi2, IL6 mRNA expression has been shown to increase following infection with $S$. Enteritidis $(27,48)$. No differences were detected in IL6 mRNA expression, but it is possible the timing of sample collection was not optimized to detect this cytokine. Additional studies are required to understand the role of IL6 and CXCLi2 expression and their impact on influencing the load of cecal colonization of $S$. Enteritidis in broilers over a grow out period.

The current study showed that a single line of birds with high and low levels of cecal colonization with $S$. Enteritidis at the time of collection have distinct kinome profiles. These data support the value of peptide arrays and kinome analysis as a powerful molecular tool to identify key mechanisms and pathways that are associated with increased resistance against $S$. Enteritidis cecal colonization in chickens. These findings provide a foundation for future studies to identify the specific markers associated with lower loads of cecal colonization and will focus on the common pathways identified herein, including chemokine, Jak-Stat, MAPK signaling pathways, or pathways in cancer. Identification of specific biomarkers that the poultry industry could use to select individual birds that are more resistant to cecal colonization with $S$. Enteritidis would be beneficial to the industry. This could potentially lead to either fewer $S$. Enteritidis positive birds entering the processing plant or reducing the load of bacteria the birds are carrying and therefore fewer positive chicken products reaching the consumer.

\section{ETHICS STATEMENT}

All experiments were conducted according to guidelines established by the USDA animal care and use committee, which operates in accordance with established principles (14). The protocol was approved by the acting USDA Plains Area animal care and use committee that operates at the location where the experiments were carried out.

\section{AUTHOR CONTRIBUTIONS}

CS was the lead investigator and principal author; $\mathrm{MK}, \mathrm{HH}, \mathrm{KG}$, CJ, and RA were collaborators and coauthors.

\section{ACKNOWLEDGMENTS}

Mention of commercial products is for the sole purpose of providing specific information, not a recommendation or endorsement by the United States Department of Agriculture.

\section{FUNDING}

This project was funded by the United States Department of Agriculture, Agricultural Research Service Project \#3091-32000034-00. 


\section{REFERENCES}

1. Cummings PL, Kuo T, Javanbakht M, Shafir S, Wang M, Sorvillo F. Salmonellosis hospitalizations in the United States: associated chronic conditions, costs, and hospital outcomes, 2011, trends 2000-2011. Foodborne Pathog Dis (2016) 13:40-8. doi:10.1089/fpd.2015.1969

2. CDC. Surveillance for Foodborne Disease Outbreaks, United States, 2014, Annual Report. Atlanta, GA: CDC (2016).

3. Manning G, Whyte DB, Martinez R, Hunter T, Sudarsanam S. The protein kinase complement of the human genome. Science (2002) 298:1912-34. doi:10.1126/science.1075762

4. Wang X-H. Progress in chemical proteomics-based kinome study. J Int Pharm Res (2014) 41:259-67. doi:10.13220/j.cnki.jipr.2014.03.001

5. Houseman BT, Huh JH, Kron SJ, Mrksich M. Peptide chips for the quantitative evaluation of protein kinase activity. Nat Biotechnol (2002) 20:270-4. doi:10.1038/nbt0302-270

6. Jalal S, Arsenault R, Potter AA, Babiuk LA, Griebel PJ, Napper S. Genome to kinome: species-specific peptide arrays for kinome analysis. Sci Signal (2009) 2:11. doi:10.1126/scisignal.254pl1

7. Arsenault RJ, Kogut MH. Chicken-specific peptide arrays for kinome analysis: flight for the flightless. Curr Topics Biotechnol (2012) 7:79-89.

8. Arsenault RJ, Napper S, Kogut MH. Salmonella enterica Typhimurium infection causes metabolic changes in chicken muscle involving AMPK, fatty acid and insulin/mTOR signaling. Vet Res (2013) 44:35. doi:10.1186/12979716-44-35

9. Ouyang Z, Takats Z, Blake TA, Gologan B, Guymon AJ, Wiseman JM, et al. Preparing protein microarrays by soft-landing of mass-selected ions. Science (2003) 301:1351-4. doi:10.1126/science.1088776

10. Swaggerty CL, Pevzner IY, Kogut MH. Selection for pro-inflammatory mediators yields chickens with increased resistance against Salmonella enterica serovar Enteritidis. Poult Sci (2014) 93:535-44. doi:10.3382/ps. 2013-03559

11. Swaggerty CL, McReynolds JL, Byrd JA, Pevzner IY, Duke SE, Genovese KJ, et al. Selection for pro-inflammatory mediators produces chickens more resistant to Clostridium perfringens-induced necrotic enteritis. Poult Sci (2016) 95:370-4. doi:10.3382/ps/pev348

12. Swaggerty CL, Pevzner IY, He H, Genovese KJ, Kogut MH. Selection for proinflammatory mediators produces chickens more resistant to Campylobacter jejuni. Poult Sci (2017) 96:1623-7. doi:10.3382/ps/pew465

13. Swaggerty CL, Pevzner IY, Kogut MH. Selection for pro-inflammatory mediators produces chickens more resistant to Eimeria tenella. Poult Sci (2015) 94:37-42. doi:10.3382/ps/peu053

14. National Research Council. Guide for the Care and Use of Laboratory Animals. 8th ed. Washington, DC: National Academies Press (2011).

15. National Research Council. Nutrient Requirements of Poultry. Washington, DC: National Academy Press (1994). p. 19-34.

16. Swaggerty CL, Ferro PJ, Pevzner IY, Kogut MH. Heterophils are associated with resistance to systemic Salmonella enteritidis infection in genetically distinct lines of chickens. FEMS Immunol Med Microbiol (2005) 43:149-54. doi:10.1016/j.femsim.2004.07.013

17. Li Y, Arsenault RJ, Trost B, Slind J, Griebel PJ, Napper S, et al. A systematic approach for analysis of peptide array kinome data. Sci Signal (2012) 5:12. doi:10.1126/scisignal.2002429

18. Arsenault RJ, Kogut $\mathrm{MH}, \mathrm{He} \mathrm{H}$. Combined $\mathrm{CpG}$ and poly I:C stimulation of monocytes results in unique signaling activation not observed with the individual ligands. Cell Signal (2013) 25(11):2246-54. doi:10.1016/j.cellsig. 2013.07.014

19. Kaiser P, Rothwell L, Galyov EE, Barrow PA, Burnside J, Wigley P. Differential cytokine expression in avian cells in response to invasion by Salmonella typhimurium, Salmonella enteritidis, and Salmonella gallinarum. Microbiology (2000) 146:3217-26. doi:10.1099/00221287-146-12-3217

20. Kogut MH, Rothwell L, Kaiser P. Differential regulation of cytokine gene expression by avian heterophils during receptor-mediated phagocytosis of opsonized and non-opsonized Salmonella enteritidis. J Interferon Cytokine Res (2003) 23:319-27. doi:10.1089/107999003766628160

21. Swaggerty CL, Pevzner IY, Kaiser P, Kogut MH. Profiling pro-inflammatory cytokine and chemokine mRNA expression levels as a novel method for selection of increased innate immune responsiveness. Vet Immunol Immunopathol (2008) 126:35-42. doi:10.1016/j.vetimm.2008.06.005
22. Refsum T, Holstad G, Kapperud G, Handeland K. An investigation of Salmonella bacteria in waterfowls and migratory birds in Norway. Acta Vet Scand (2005) 46:95-100.

23. Hotson AN, Gopinath S, Nicolau M, Khasanova A, Finck R, Monack D, et al. Coordinate actions of innate immune responses oppose those of the adaptive immune system during Salmonella infection of mice. Sci Signal (2016) 9:ra4. doi:10.1126/scisignal.aaa9303

24. Nakamura M, Nagamine N, Suzuki S, Norimatsu M, Oishi K, Kijima M, et al. Long-term shedding of Salmonella enteritidis in chickens which received a contact exposure within 24 hrs of hatching. J Vet Med Sci (1993) 55: 649-53. doi:10.1292/jvms.55.649

25. Van Immerseel F, De Buck J, Pasmans F, Bohez L, Boyen F, Haesebrouck F, et al. Intermittent long-term shedding and induction of carrier birds after infection of chickens early posthatch with a low or high dose of Salmonella enteritidis. Poult Sci (2004) 83:1911-6. doi:10.1093/ps/83.11.1911

26. Coussens PM, Verman N, Coussens MA, Elftman MD, McNulty AM. Cytokine gene expression in peripheral blood mononuclear cells and tissues of cattle infected with Mycobacterium avium subsp. paratuberculosis: evidence for an inherent proinflammatory gene expression pattern. Infect Immun (2004) 72:1409-22. doi:10.1128/IAI.72.3.1409-1422.2004

27. Ferro PJ, Swaggerty CL, Kaiser P, Pevzner IY, Kogut MH. Heterophils isolated from chickens resistant to extraintestinal Salmonella enteritidis infection express higher levels of pro-inflammatory cytokine mRNA following infection than heterophils from susceptible chickens. Epidemiol Infect (2004) 132:1029-37. doi:10.1017/S0950268804002687

28. Heinrich JM, Bernheiden M, Minigo G, Yang KK, Schutt C, Mannel DN, et al. The essential role of lipopolysaccharide-binding protein in protection of mice against a peritoneal Salmonella infection involves the rapid induction of an inflammatory response. J Immunol (2001) 167:1624-8. doi:10.4049/ jimmunol.167.3.1624

29. Sebastiani G, Blais V, Sancho V, Vogel SN, Stevenson MM, Gros P, et al. Host immune response to Salmonella enterica serovar Typhimurium infection in mice derived from wild strains. Infect Immun (2002) 70:1997-2009. doi:10.1128/IAI.70.4.1997-2009.2002

30. Withanage GSK, Kaiser P, Wigley P, Powers C, Mastroeni P, Brooks H, et al. Rapid expression of chemokines and proinflammatory cytokines in newly hatched chickens infected with Salmonella enterica serovar Typhimurium. Infect Immun (2004) 72:2152-9. doi:10.1128/IAI.72.4.2152-2159.2004

31. Hasenstein JR, Hassen AT, Dekkers JC, Lamont SJ. High resolution, advanced intercross mapping of host resistance to Salmonella colonization. Dev Biol (2008) 132:213-8. doi:10.1159/000317162

32. Swaggerty CL, He H, Genovese KJ, Pevzner IY, Kogut MH. Protein tyrosine kinase and mitogen-activated protein kinase signaling pathways contribute to differences in heterophil-mediated innate immune responsiveness between two lines of broilers. Avian Pathol (2011) 40:289-97. doi:10.1080/0307945 7.2011 .565310

33. Genovese KJ, He H, Lowry VK, Kogut MH. Comparison of MAP and tyrosine kinase signaling in heterophils from commercial and wild-type turkeys. Dev Comp Immunol (2007) 31:927-33. doi:10.1016/j.dci.2006.12.002

34. Ibarra JA, Steele-Mortimer O. Salmonella - the ultimate insider. Salmonella virulence factors that modulate intracellular survival. Cell Microbiol (2009) 11:1579-86. doi:10.1111/j.1462-5822.2009.01368.x

35. Ramos-Morales F. Impact of Salmonella enterica type III secretion system effectors on the eukaryotic host cell. ISRN Cell Biol (2012) 2012:36. doi:10.5402/2012/787934

36. Uchiya K, Nikai T. Salmonella virulence factor SpiC is involved in expression of flagellin protein and mediates activation of the signal transduction pathways in macrophages. Microbiology (2008) 154:3491-502. doi:10.1099/ mic.0.2008/021667-0

37. Radu M, Chernoff J. Recent advances in methods to assess the activity of the kinome. F1000Research (2017) 6:1004. doi:10.12688/f1000research. 10962.1

38. Van Wyk B, Snider M, Scruten E, van Drunen Littel-van den Hurk S, Napper S. Induction of functional interferon alpha and gamma responses during acute infection of cattle with non-cytopathic bovine viral diarrhea virus. Vet Microbiol (2016) 195:104-14. doi:10.1016/j.vetmic.2016.09.015

39. Arsenault RJ, Jalal S, Babiuk LA, Potter A, Griebel PJ, Napper S. Kinome analysis of Toll-like receptor signaling in bovine macrophages. J Recept Signal Transduct Res (2009) 29:299-311. doi:10.3109/10799890903295127 
40. Arsenault RJ, Li Y, Bell K, Doig K, Potter A, Griebel PJ, et al. Mycobacterium avium subsp. paratuberculosis inhibits gamma interferon-induced signaling in bovine monocytes: insights into the cellular mechanisms of Johne's disease. Infect Immun (2012) 80:3039-48. doi:10.1128/IAI.00406-12

41. Kogut MH, Swaggerty CL, Byrd JA, Selvaraj R, Arsenault RJ. Chicken-specific kinome array reveals that Salmonella enterica serovar Enteritidis modulates host immune signaling pathways in the cecum to establish a persistence infection. Int J Mol Sci (2016) 17:E1207. doi:10.3390/ijms17081207

42. Bar-Shira E, Friedman A. Development and adaptations of innate immunity in the gastrointestinal tract of the newly hatched chick. Dev Comp Immunol (2006) 30:930-41. doi:10.1016/j.dci.2005.12.002

43. Sadeyen JR, Trotereau J, Velge P, Marly J, Beaumont C, Barrow PA, et al. Salmonella carrier state in chicken: comparison of expression of immune response genes between susceptible and resistant animals. Microb Infect (2004) 6: 1278-86. doi:10.1016/j.micinf.2004.07.005

44. Kogut MH. Dynamics of a protective avian inflammatory response: the role of an IL-8-like cytokine in the recruitment of heterophils to the site of organ invasion by Salmonella enteritidis. Comp Immunol Microbiol Infect Dis (2002) 25:159-72. doi:10.1016/S0147-9571(01)00035-2

45. Rychlik I, Elsheimer-Matulova M, Kyrova K. Gene expression in the chicken caecum in response to infections with non-typhoid Salmonella. Vet Res (2014) 45:119. doi:10.1186/s13567-014-0119-2
46. Shaughnessy RG, Meade KG, Cahalane S, Allan B, Reiman C, Callanan JJ, et al. Innate immune gene expression differentiates the early avian intestinal response between Salmonella and Campylobacter. Vet Immunol Immunopathol (2009) 132:191-8. doi:10.1016/j.vetimm.2009.06.007

47. Tohidi R, Idris IB, Panandam JM, Hair-Bejo M. Early immune gene expression responses to Salmonella enteritidis infection in indigenous chickens. J Appl Anim Res (2014) 42:204-7. doi:10.1080/09712119.2013.825619

48. Cheeseman JH, Kaiser MG, Ciraci C, Kaiser P, Lamont SJ. Breed effect on early cytokine mRNA expression in spleen and cecum of chickens with and without Salmonella enteritidis infection. Dev Comp Immunol (2007) 31:52-60. doi:10.1016/j.dci.2006.04.001

Conflict of Interest Statement: The authors declare the research was conducted in the absence of any commercial and/or financial relationship that could be construed as a potential conflict of interest.

Copyright (c) 2017 Swaggerty, Kogut, He, Genovese, Johnson and Arsenault. This is an open-access article distributed under the terms of the Creative Commons Attribution License (CC BY). The use, distribution or reproduction in other forums is permitted, provided the original author(s) or licensor are credited and that the original publication in this journal is cited, in accordance with accepted academic practice. No use, distribution or reproduction is permitted which does not comply with these terms. 